\title{
Novel three-dimensional in vitro models of ovarian endometriosis
}

\author{
Doerthe Brueggmann ${ }^{1}$, Claire Templeman ${ }^{1}$, Anna Starzinski-Powitz², Nagesh P Rao ${ }^{3}$, Simon A Gayther ${ }^{4 *}$ \\ and Kate Lawrenson ${ }^{4}$
}

\begin{abstract}
Background: Endometriosis is characterized by the presence of functional endometrial tissue outside of the uterine cavity. It affects 1 in 10 women of reproductive age. This chronic condition commonly leads to consequences such as pelvic pain, dysmenorrhea, infertility and an elevated risk of epithelial ovarian cancer. Despite the prevalence of endometriosis and its impact on women's lives, there are relatively few in vitro and in vivo models available for studying the complex disease biology, pathophysiology, and for use in the preclinical development of novel therapies. The goal of this study was to develop a novel three-dimensional (3D) cell culture model of ovarian endometriosis and to test whether it is more reflective of endometriosis biology than traditional two dimensional (2D) monolayer cultures.
\end{abstract}

Methods: A novel ovarian endometriosis epithelial cell line (EEC16) was isolated from a 34-year old female with severe endometriosis. After characterization of cells using in vitro assays, western blotting and RNA-sequencing, this cell line and a second, already well characterized endometriosis cell line, EEC12Z, were established as in vitro 3D spheroid models. We compared biological features of 3D spheroids to 2D cultures and human endometriosis lesions using immunohistochemistry and real-time semi-quantitative PCR.

Results: In comparison to normal ovarian epithelial cells, EEC16 displayed features of neoplastic transformation in in vitro assays. When cultured in 3D, EEC16 and EEC12Z showed differential expression of endometriosis-associated genes compared to 2D monolayer cultures, and more closely mimicked the molecular and histological features of human endometriosis lesions.

Conclusions: To our knowledge, this represents the first report of an in vitro spheroid model of endometriosis. 3D endometriosis models represent valuable experimental tools for studying EEC biology and the development of novel therapeutic approaches.

Keywords: Ovary, Endometriosis, Cell culture, Three-dimensional in vitro modeling, Real-time semi-quantitative PCR, RNA sequencing

\section{Background}

Endometriosis is a chronic condition affecting around 10\% of reproductive age women [1]. Typically, functional endometrial tissue is present outside the uterine cavity and results in symptoms that include pelvic pain, dysmenorrhea and dyspareunia [2]. Endometriosis patients often experience infertility and are at an elevated risk of epithelial ovarian cancer [2,3]. Endometriosis can be classified into three

\footnotetext{
* Correspondence: gayther@usc.edu

${ }^{4}$ Department of Preventive Medicine, University of Southern California/Keck School of Medicine, Harlyne Norris Research Tower, NRT2517G, 1450 Biggy Street, Los Angeles, California 90033, USA

Full list of author information is available at the end of the article
}

subtypes: lesions in the pelvic peritoneum; ovarian endometriosis that may occur as superficial lesions on the surface of the ovary or as cysts lined with endometrioid epithelium (endometrioma); and deep-infiltrating lesions of the rectovaginal septum $[2,4]$. Ovarian endometriosis is of particular interest, as a proportion of ovarian cancers arise from ovarian endometriotic lesions, particularly clear cell and endometrioid ovarian carcinomas [5,6].

Despite the prevalence of endometriosis and its significant impact on women's lives, there are relatively few in vitro and in vivo models available for studying the complex disease biology, pathophysiology, and for use in the

\section{Biomed Central}


preclinical development of novel therapies. One widely used in vitro model comprises cell lines of epithelial (EEC12Z) and stromal (ESC22B) origin harvested from peritoneal endometriosis lesions [7-9]. Co-injection of these cells into mice results in peritoneal lesions that recreate histological features of human endometriosis in vivo [8]. This particular model has been used to study various aspects of endometriosis cell biology including hormone signaling, cell-cell adhesions, as well as to conduct candidate gene studies [9-11]. However, this model was established from a peritoneal lesion, and there is a real need for additional models that mimic other subtypes of this disease in order to better understand the pathophysiology of endometriosis subtypes, and for the development of new treatment strategies.

A major limitation of existing in vitro models of endometriosis is that they have been established by culturing endometriosis epithelial cells (EECs) as monolayers on tissue culture plastics (i.e. as two-dimensional (2D) cultures). In vivo, EECs exist within a dynamic three-dimensional (3D) microenvironment and constantly interact with a stroma containing immune cells, fibroblasts, vasculature and a heterogeneous network of extracellular matrix. Endometriosis cells in vivo also form cell-cell interactions through the entire cell surface. By contrast, cells in 2D can only interact along a small proportion of the plasma membrane. Several studies have now reported on improvements in in vitro modeling of several diseases when target cells are cultured as 3D models; cultured cells maintained in 3D resemble the tissues of origin more closely than the same cells cultured in 2D [12-14]. However, to our knowledge, there are no studies reporting in vitro spheroid models of endometriosis. Such models could be particularly useful for developing novel therapies for this disease [15] and for studying the links between endometriosis and ovarian cancer.

To better model the biology of ovarian surface endometriosis, we have established and characterized a novel endometriosis epithelial cell (EEC) line, EEC16, from a 34-year old patient diagnosed with ovarian endometriosis. EEC16 and a second endometriosis cell line (EEC12Z) from a patient with peritoneal endometriosis were established as in vitro $3 \mathrm{D}$ cell culture models and the morphological and molecular features evaluated. EECs grown as 3D cultures mimic endometriosis lesions in vivo more closely than $2 \mathrm{D}$ cultured counterparts, suggesting that these models are robust representations of human endometriosis for future use in understanding the etiology of endometriosis and identifying novel therapeutic targets for the disease.

\section{Methods}

\section{Primary tissue collection}

Endometriosis cells (EEC16) were isolated from a 34year pre-menopausal patient with severe, histologically confirmed endometriosis. EEC16 cells were collected from a superficial endometriosis lesion on the surface of the ovary. The ovary of the patient was removed at surgery and the ovarian surface brushed with a sterile cytobrush that was then placed into $7 \mathrm{mls}$ culture medium and agitated to release the cells.

Normal ovarian epithelial cells (OSEC10, OSEC181 and OSEC11) were obtained from women undergoing gynecological surgery for conditions that did not involve the ovaries (endometrial carcinoma or hyperplasia). Cells were collected by brushing the ovaries with a sterile cytobrush, as described above. Ovaries were confirmed to be free of disease by histopathological assessment. All OSECs used in this study are morphologically and phenotypically similar and are representative of the $\sim 80$ OSEC cell lines we have characterized in our laboratory. The cellcontaining medium was transported to the tissue culture laboratory and transferred to a $25 \mathrm{~cm}^{2}$ tissue culture flask. Cell growth was monitored by phase microscopy, and cells were fed twice weekly. Once cells reached $80 \%$ confluency, the culture was passaged.

For histology and real-time PCR experiments, tissue samples were obtained from patients undergoing laparoscopy at Keck Hospital of USC for endometriosis or other benign gynecological conditions. Biopsy material was transferred in either RPMI media (Sigma-Aldrich, United States) or RNAlater (Ambion, United States) and stored at $-80^{\circ} \mathrm{C}$.

\section{Cell culture}

Endometriosis epithelial cells (EEC16) and OSECs were maintained in NOSECM [16]: MCDB105:Medium 199 (mixed in a 1:1 ratio) supplemented with $15 \%$ fetal bovine serum (FBS, Hyclone, United States), $10 \mathrm{ng} / \mathrm{ml}$ epidermal growth factor, $0.5 \mathrm{mg} / \mathrm{ml}$ hydrocortisone, $5 \mathrm{mg} / \mathrm{ml}$ insulin, and $34 \mathrm{mg}$ protein $/ \mathrm{ml}$ bovine pituitary extract, (all Sigma, United States) plus penicillin/streptomycin (Mediatech, United States). SV40 transformed endometriosis epithelial cells (EEC12Z) [17] were cultured in Dulbecco's Minimal Essential Medium supplemented with 10\% fetal bovine serum (FBS, PAA Laboratories, Austria) and penicillin/ streptomycin (Mediatech, United States). Control cells for anchorage-independent growth assays and Western blotting (MCF7, MDA-MB-231, IGROV and SKOV 3) were grown in the media recommended by ATCC or The Lawrence Berkeley National Laboratory [18]. All cell lines used in this study were routinely tested for mycoplasma infection.

\section{EEC16 in vitro characterization}

To perform Western blot analysis of marker expression, cells were harvested at $80 \%$ confluency, were washed twice in phosphate buffered saline (PBS) and then lysed using Triton-X lysis buffer (20 mM Tris-Cl pH 7.5, 150 
$\mathrm{mM} \mathrm{NaCl}, 1 \%$ Triton-X 100, $1.2 \mu \mathrm{g} / \mathrm{ml}$ aproptinin, 100 $\mu \mathrm{g} / \mathrm{ml}$ leupeptin, and $1 \mathrm{mM}$ phenylmethylsulfonyl fluoride, all purchased from Sigma, United States). Lysates were rotated at $4^{\circ} \mathrm{C}$ for 30 mins before clearing insoluble proteins by centrifugation for $10 \mathrm{mins}$ at $4^{\circ} \mathrm{C}$ at 14000 rpm. Protein concentrations were determined using the Coomassie Plus Protein Assay (Thermo Scientific, United States), according to manufacturer's instructions. 5-10 $\mu \mathrm{g}$ protein was denatured and separated using SDSpolyacrylamide gel electrophoresis. Proteins were transferred onto polyvinylidene fluoride membranes overnight, and probed using standard protocols. The antibodies used were pan-cytokeratin (sc-8018, Santa Cruz, United States), vimentin (clone VIM 3B4, Millipore, United States), Estrogen Receptor $\alpha$ (ER $\alpha$, sc-543, Santa Cruz, United States), E-Cadherin (clone EP700Y, Millipore, United States), P-Cadherin (clone 12H6, Invitrogen, United States), NCadherin (clone 3B9, Invitrogen, United States) and $\beta$-actin (A5060, Sigma, United States). All primary antibodies were used at a 1:1,000 dilution except for antiE-Cadherin, which was used at a 1:5,000 dilution.

Chromosomal analyses and karyotyping were performed at Pathology and Lab Medicine, David Geffen University of California Los Angeles. Cells were plated into a $25 \mathrm{~cm}^{2}$ flask and harvested when subconfluent. Cells were Giemsa-banded following routine cytogenetic methods. Twenty metaphase cells were analyzed and karyotyped under a Zeiss bright field microscope (Zeiss, Germany) equipped with image analysis hardware and software.

To perform growth curves, $1 \times 10^{5}$ cells were plated in triplicate. Cultures were passaged when they reached $80 \%$ confluency and population doublings (PD) were calculated using the following formula:

$\mathrm{PD}=\log$ (total cell number on day $\mathrm{N} /$ initial cell number) $/ \log 2$.

For migration and invasion assays, cells were starved for 24 hours, and applied to cell permeable transwell inserts, in triplicate. For migration assays, $3 \times 10^{4}$ cells were applied to migration inserts (Greiner Bio One, Austria); for invasion assays, $0.125 \times 10^{6}$ cells were applied to rehydrated QCM ECMatrix invasion chambers (Millipore, United States). $10 \%$ FBS was used as a chemoattractant. After 24 hours, remaining cells were removed from the upper chamber of the inserts. To quantify migration, membranes were fixed in 100\% methanol (VWR, United States), stained with crystal violet solution (Sigma, United States; $5 \mathrm{mg} / \mathrm{ml}$ in $2 \%$ ethanol (VWR, United States) and cells were counted by brightfield microscopy. Fluorimetric quantification of invaded cells was performed according to the manufacturer's instructions. Anchorage independent growth assays were performed by plating $2 \times 10^{4}$ cells in culture medium containing $0.3 \%$ Noble
Agar (Sigma, United States) over a base layer of complete medium containing $0.6 \%$ Noble Agar. Five replicates were plated for each cell line; SKOV3 ovarian cancer cells served as a positive control. After 4 weeks, cells were fixed and stained with $1 \% \mathrm{p}$-iodonitrotetrazolium violet (Sigma, United States) in 100\% methanol (VWR, United States). Colonies were counted using phase microscopy. To test for phenotypic differences between cell lines, two-tailed unpaired Student's T-tests were used.

\section{RNA-sequencing analysis and gene ontology analyses}

RNA was extracted from EEC16 and OSEC11 cultures using the Illustra RNAspin mini kit with on column DNase treatment (GE Healthcare, United States) according to manufacturer's guidelines. RNA-sequencing was performed at the USC Epigenome Core Facility. Briefly, RNA samples were quality checked (QC'd) using the Agilent Bioanalyzer (Agilent Technologies, United States) and polyA RNA-seq cDNA libraries prepared the TruSeq ${ }^{\mathrm{Tm}}$ RNA sample prep kit (Illumina, United States). Libraries were barcoded and 4 samples multiplexed per lane for sequencing on the Illumina $\mathrm{HiSeq}^{\mathrm{mm}} 2000$ using 50 bp paired-end reads. Data were exported, QC'd and analysed using SimBiot software. QC'd data were mapped to the genome using TopHat, normalized gene expression quantified using Cufflinks and differential expression analyses performed using CuffDiff. Gene ontology (GO) analyses were performed using DAVID (http://david.abcc.ncifcrf.gov/) for all genes significantly differentially expressed between EEC16 and OSEC11 after adjustment for multiple testing (q value $<0.05$ ). GO terms with a Benjamini-adjusted $\mathrm{p}$-value $<0.05$ were considered to be significantly enriched for in this dataset. RNA-seq data have been deposited onto the Gene Expression Omnibus (http://www.ncbi.nlm.nih.gov/geo/, GEO number to be confirmed by time of publication).

\section{Three-dimensional cell culture, histology and immunohistochemistry}

Cell culture plastics (diameter: $100 \mathrm{~mm}$ ) were twice coated with $1.5 \%$ polyHEMA (Sigma, United States) dissolved in $95 \%$ ethanol (VWR, United States). Coated plates were allowed to dry completely before use. Coated plates were washed for $\sim 5$ mins with $1 \times$ PBS and 1-3 $\times$ $10^{6}$ cells were added in a final culture volume of $20 \mathrm{mls}$. Cultures were fed twice weekly before processing into paraffin or RNA extraction. The diameter of the spheroids was assessed by brightfield microscopy.

For paraffin embedding, human endometriosis tissue and spheroids were fixed in neutral buffered formalin (30 mins, at room temperature), washed and transferred into $70 \%$ ethanol. The samples were processed into paraffin, sectioned and stained with H\&E at the USC Surgical Pathology Laboratory. Immunohistochemical staining was performed at the USC Department of Pathology Immunohistochemistry Laboratory. 


\section{RNA extraction and gene expression analysis}

RNA was extracted from 2D and 3D cultured cells and human endometriosis tissue samples as described above; after mechanical disruption, samples were lysed using $350 \mu \mathrm{l}$ RA1 lysis buffer (containing 1\% $\beta$-mercaptoethanol). Samples were quantified and reverse-transcribed using qScript and random hexamer primers (Quanta Biosciences, United States). The final PCR mixture contained $0.5 \mu \mathrm{l}$ each of forward and reverse primers (final concentration of 100-500 $\mathrm{nM}$, primer sequences in Additional file 1: Table S1), 12.5 $\mu \mathrm{l} 2 \times$ SYBR PCR mix (Quanta Biosciences, United States), and $1 \mu \mathrm{l} \mathrm{cDNA}$. Using an ABI 7900HT Fast Real-Time PCR system (Applied Biosystems, United States), the samples were run using the following conditions: 2 mins at $50^{\circ} \mathrm{C}, 10$ mins at $95^{\circ} \mathrm{C}, 40$ cycles of 15 secs at $95^{\circ} \mathrm{C}$, and $1 \mathrm{~min}$ at $60^{\circ} \mathrm{C}$. Data were standardized in relation to the house-keeping gene $G A P D H$ and analyzed using the $\triangle \triangle \mathrm{Ct}$ relative quantification method. To compare changes in gene expression in 2D and 3D, two-tailed paired Student's T-tests were performed.

\section{Ethical approval}

For primary cell culture, tissues were collected, with informed consent, under the approval of the University College London/University College London Hospitals UCL/UCLH Ethics Committee. The collection of endometriosis tissue for real-time PCR experiments was approved by the USC Institutional Review Board.

\section{Results}

\section{Establishing a novel in vitro model of endometriosis} epithelial cells

We established an endometriosis epithelial cell line (EEC16) from an ovarian endometriosis lesion in a patient with severe endometriosis. Cells displayed an epithelial morphology with mesenchymal characteristics (Figure 1A). We evaluated the expression of several biomarkers and found that EEC16 expressed cytokeratin and vimentin, but did not express $\mathrm{N}$-Cadherin, ER $\alpha$ or P-Cadherin (Figure 1B). Unexpectedly, EEC16 did also not express E-Cadherin, and so we analyzed expression of the $C D H 1$ gene in primary human ovarian endometriosis tissues and normal endometrial biopsies. We observed that $C D H 1$ gene expression is significantly lower in human ovarian endometriosis tissues compared to eutopic endometrium (in eutopic endometrium, $\mathrm{CDH} 1$ expression is independent on the cycle phase, Additional file 2: Figure S1), which suggests the lack of E-Cadherin expression by EEC16 is not atypical for ovarian endometriosis (Figure 1C). The EEC16 line was karyotypically normal (46,XX) (Figure 1D). Critically, EEC16 biomarker expression differed from that of a normal ovarian surface epithelial cell line harvested from the ovary of a woman unaffected by endometriosis and so was not the result of outgrowth of contaminating ovarian epithelial cells.

The in vitro phenotype differed significantly between EEC16 and normal ovarian surface epithelial cells (OSECs). We also compared the phenotype of this newly established EEC16 line to a previously described epithelial cell line generated from a peritoneal endometriotic lesion (EEC12Z) and immortalized with the SV40 large $\mathrm{T}$ antigen [17]. Typical of normal, primary cells in culture, both EEC16 and OSEC cultures had a limited in vitro lifespan (Figure 1E). By contrast, the immortalized EEC12Z line did not show any signs of crisis or senescence even after extended passaging in culture (Figure 1E) [17]. Unlike OSECs, EEC16 cultures exhibited phenotypes typically associated with neoplastic transformation. EEC16 formed colonies in anchorage independent growth assays (Figure 1F). Colonies formed by EEC16 in the anchorage-independent growth assays were fewer in number than those formed by EEC12Z (unpaired T-test, $\mathrm{P}>0.05$ ), suggesting EEC16 has a less transformed phenotype than EEC12Z. However, the EEC16 line was more migratory and invasive compared to normal OSECs (unpaired T-test, $\mathrm{P}>0.05$, Figure 1 G\&H) but did not differ from EEC12Z in these characteristics. EEC16 was non-transformed in vivo and did not reproducibly form lesions when xenografted into nude mice (data not shown). Overall, EEC16 and EEC12Z lines show morphological, phenotypic and molecular characteristics that reflect features typical of human endometriosis lesions and have a more transformed phenotype in vitro than OSEC cells.

\section{Whole transcriptome analysis of EEC16}

We performed RNA-sequencing to compare the transcriptome between primary EEC16 and OSEC lines. There were 1780 genes significantly differentially expressed between the two cell lines (q value $<0.05$ ). The top differentially expressed genes are listed in Table 1. Genes that were expressed more highly in EEC16 included hyaluronan synthase 1 , keratin 19 , cadherin 20 and genes of the aldehyde dehydrogenase 1 family; genes expressed at lower levels in EEC16 included homeobox $\mathrm{C} 11$ and $\mathrm{C} 12$, renin, superoxide dismutase 3 , and calcitonin receptor. Gene ontology analysis showed that the EEC16 transcriptome was significantly enriched for genes expressed in the extracellular milieu compared to OSECs (Benjamini adjusted $\mathrm{p}=2.29 \times 10^{-15}$ ). The most significantly enriched biological processes were adhesion (adjusted $\mathrm{p}=1.08 \times 10^{-11}$ ) and vasculature development (adjusted $\mathrm{p}=6.49 \times 10^{-10}$ ) (Figure 2). We also observed significant enrichment of genes associated with migration and cell contractility, inflammatory responses, and responses to hypoxia (Additional file 3: Table S2). 
A
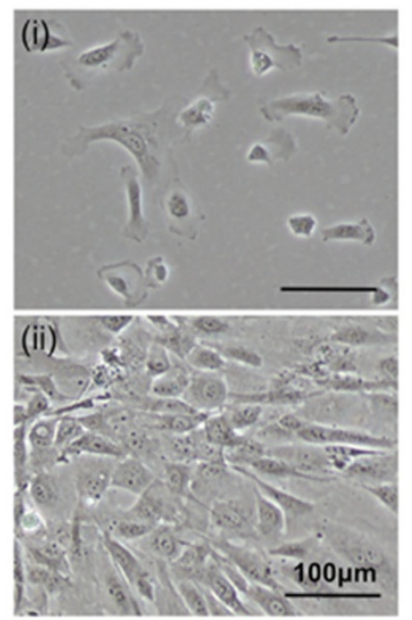

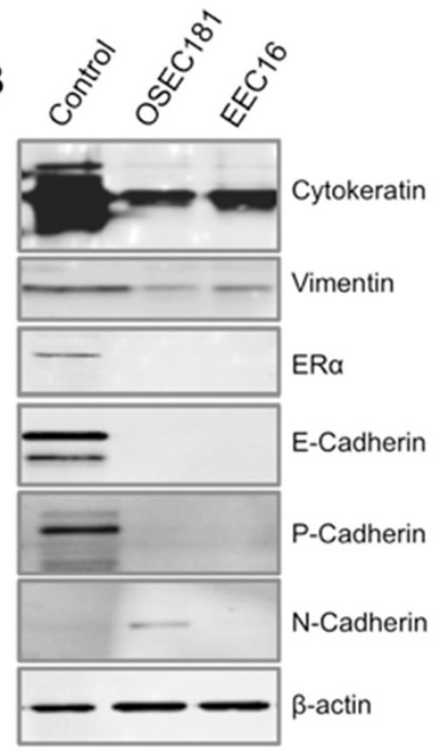

C

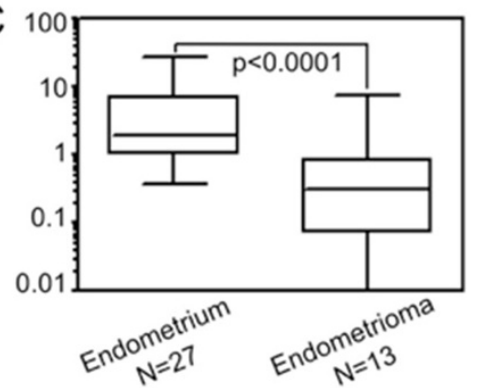

D

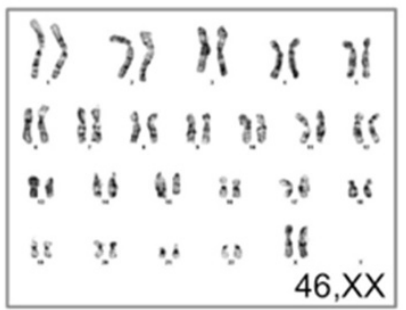

E

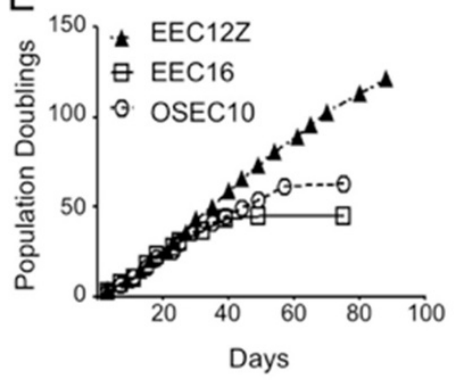

$\mathrm{F}$

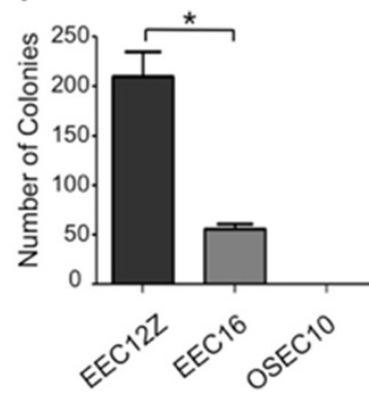

G

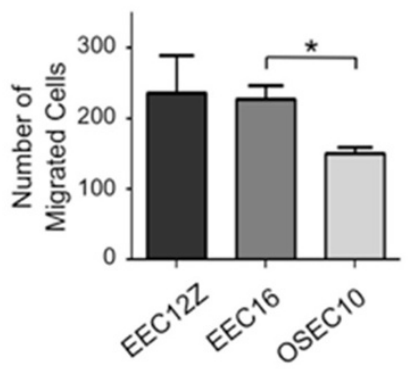

$\mathrm{H}$

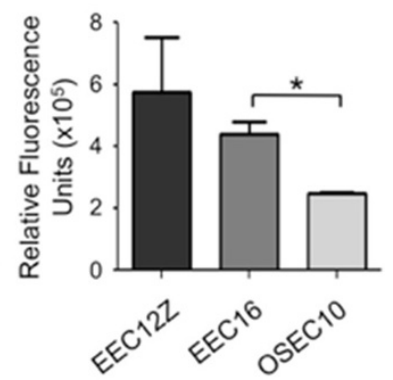

Figure 1 In vitro characterization of a novel primary ovarian endometriosis epithelial cell line, EEC16. (A) EEC16 cells have a mesenchymal-type epithelial morphology in vitro at (i) low cell density and (ii) high seeding density. (B) Western blot analysis of marker expression. The EEC16 line expressed cytokeratin and vimentin. EEC16 does not express ERa, E-, P-, or N-Cadherin. Beta-actin was used as a loading control. Control lysates used were breast and ovarian cancer cell lines: MCF7, for cytokeratin; T47D, for ERa and P-Cadherin; MDA-MB-231 for vimentin; BT549 for N-Cadherin; and IGROV for E-Cadherin. The difference in ovarian surface epithelial cell (OSEC181) and EEC16 profiles indicates that the EEC16 line is unlikely to be contaminated with normal OSECS. (C) Real-time PCR analysis of primary endometrioma and endometrial tissues, $\mathrm{CDH} 1$ is downregulated in endometrioma tissues compared to eutopic endometrium. Expression of $\mathrm{CDH} 1$ in endometrium of women without endometriosis is independent on the stage of the menstrual cycle (Additional file 2: Figure S1). (D) The EEC16 line has a normal, female karyotype. (E) Growth curves. The EEC16 and OSEC10 lines have a finite in vitro lifespan. In comparison, the SV40T-expressing EEC12Z endometriosis line, which has spontaneously acquired the ability to evade replicative crisis, did not show any signs of senescence after extended time in culture [17]. (F) In anchorage-independent growth assays the EEC12Z line forms significantly more colonies than EEC16. EEC16 formed colonies in agar up until passage 11. OSEC10 fails to form colonies in soft agar. EEC16 cells are significantly more (G) migratory and (H) invasive than OSEC10. Each assay was performed three times. ${ }^{*} P>0.05$, two-tailed unpaired T-test.

\section{Establishing three-dimensional models of human endometriosis}

We established EEC16 and EEC12Z as in vitro 3D models by culturing cells in non-adherent conditions using polyHEMA-coated cell culture plastics. Both EEC16 and EEC12Z lines began to aggregate within 24 hours and formed smooth, symmetrical spheroid structures (Figure 3A). After 7 days of culturing EEC16 spheroids measured $79.3 \pm 15.5 \mu \mathrm{m}$ in diameter. EEC12Z spheroids were significantly larger in size, measuring $225.7 \pm 23.7 \mu \mathrm{m}$ in diameter (unpaired T-test, $\mathrm{P}>0.05$ ).
The histological and molecular features of the 3D EEC models were compared with primary human endometriotic lesions. Analysis of hematoxylin and eosin stained sections showed that EEC spheroids were highly cellular and bore histological similarities to human endometriosis tissues such as lesions in the uterosacral ligament and in the peritoneum (Figure 3A). Immunohistochemical staining revealed that $100 \%$ of EEC 16 and 12 expressed cytokeratin. Staining intensity for cytokeratin was increased in cells grown in 3D compared with 2D. Finally, 3D cultures of EEC16 had lower proliferative 
Table 1 RNA sequencing shows significant differences in transcriptomes of the EEC16 and OSEC lines

\begin{tabular}{|c|c|c|c|c|c|}
\hline Gene symbol & Gene name & $\begin{array}{l}\text { OSEC11 } \\
\text { expression }\end{array}$ & $\begin{array}{l}\text { EEC16 } \\
\text { expression }\end{array}$ & Fold change & q-value \\
\hline \multicolumn{6}{|c|}{ Highly expressed in EEC16 } \\
\hline HAS1 & Hyaluronan synthase 1 & 0.19 & 148.84 & 777.83 & $0.00 \mathrm{E}+00$ \\
\hline NCAM1 & Neural cell adhesion molecule 1 & 0.02 & 11.33 & 524.29 & $3.44 \mathrm{E}-08$ \\
\hline CHL1 & Cell adhesion molecule with homology to LICAM & 0.06 & 29.64 & 491.01 & $0.00 \mathrm{E}+00$ \\
\hline KRT19 & Keratin 19 & 0.74 & 253.34 & 341.72 & $0.00 \mathrm{E}+00$ \\
\hline PAQR5,Y_RNA & Progestin and adipoQ receptor family member $V$ & 0.34 & 101.55 & 301.90 & 3.07E-03 \\
\hline ODZ2 & Odz, odd Oz/ten-m homolog 2 (Drosophila) & 0.05 & 13.68 & 288.70 & 1.19E-06 \\
\hline FBLN2 & Fibulin2 & 0.44 & 108.01 & 246.49 & 4.84E-11 \\
\hline SLC24A3 & Solute carrier family 24 (sodium/potassium/calcium exchanger), member 31 & 0.02 & 4.47 & 244.08 & 4.34E-06 \\
\hline $\mathrm{CDH} 2 \mathrm{O}$ & Cadherin 20, type 2 & 0.05 & 12.94 & 242.76 & $5.11 \mathrm{E}-07$ \\
\hline MST1R & Macrophage stimulating 1 receptor (c-met-related tyrosine kinase) & 0.02 & 4.09 & 238.53 & $2.60 \mathrm{E}-03$ \\
\hline SLITRK5 & SLIT and NTRK-like family, member 5 & 0.02 & 3.76 & 236.12 & 4.86E-06 \\
\hline KRT19P1 & Keratin 19 pseudogene 1 & 0.07 & 15.32 & 222.27 & $6.83 \mathrm{E}-06$ \\
\hline CATSPER2 & Cation channel, sperm associated 2 & 0.01 & 2.39 & 172.42 & 1.99E-04 \\
\hline SLC35F3 & Solute carrier family 35 , member F3 & 0.03 & 3.89 & 147.18 & $6.17 \mathrm{E}-03$ \\
\hline CCDC85A & Coiled-coil domain containing 85A & 0.04 & 5.32 & 145.01 & $1.46 \mathrm{E}-03$ \\
\hline $\mathrm{ALDH} 1 \mathrm{~A} 2$ & Aldehyde dehydrogenase 1 family, member A2 & 0.16 & 21.60 & 137.26 & $0.00 E+00$ \\
\hline NOVA1 & Neuro-oncological ventral antigen 1 & 0.04 & 4.50 & 123.52 & $6.61 \mathrm{E}-09$ \\
\hline NEBL & Nebulette, Actin-binding Z-disk protein & 0.22 & 26.32 & 122.11 & $3.89 \mathrm{E}-13$ \\
\hline AC121334.1,KIF21A & Kinesin family member $21 \mathrm{~A}$ & 7.08 & 804.71 & 113.71 & $6.09 \mathrm{E}-04$ \\
\hline ST6GALNAC3 & ST6 (alpha-N-acetyl-neuraminyl-2,3-beta-galactosyl-1,3)-N-acetylgalactosaminide alpha-2,6-sialyltransferase 3 & 0.02 & 2.17 & 107.18 & $6.71 \mathrm{E}-08$ \\
\hline PMS2 & PMS2 postmeiotic segregation increased 2 (S. cerevisiae) & 4.99 & 524.34 & 105.00 & $1.84 \mathrm{E}-05$ \\
\hline MMEL1 & Membrane metallo-endopeptidase-like 1 & 0.04 & 4.06 & 99.76 & 1.19E-02 \\
\hline SULT1E1 & Sulfotransferase family $1 \mathrm{E}$, estrogen-preferring, member 1 & 0.19 & 18.17 & 94.01 & $2.70 \mathrm{E}-05$ \\
\hline PTPRD & Protein tyrosine phosphatase, receptor type, D & 0.03 & 2.64 & 90.18 & $2.44 \mathrm{E}-03$ \\
\hline FBN2 & Fibrillin 2 & 0.43 & 36.94 & 86.48 & $0.00 E+00$ \\
\hline DIRAS3 & DIRAS family, GTP-binding RAS-like 3 & 3.47 & 281.89 & 81.34 & $0.00 E+00$ \\
\hline DSC2 & Desmocollin 2 & 0.06 & 4.98 & 80.65 & $1.02 \mathrm{E}-09$ \\
\hline CD7 & CD7 molecule, T-cell leukemia antigen & 0.78 & 62.57 & 80.60 & $1.34 \mathrm{E}-11$ \\
\hline RSPO4 & R-spondin 4 & 0.03 & 2.29 & 78.55 & $1.92 \mathrm{E}-02$ \\
\hline C3AR1 & Complement component 3a receptor 1 & 0.07 & 5.56 & 77.19 & $5.05 \mathrm{E}-05$ \\
\hline
\end{tabular}


Table 1 RNA sequencing shows significant differences in transcriptomes of the EEC16 and OSEC lines (Continued)

\begin{tabular}{|c|c|c|c|c|c|}
\hline \multicolumn{6}{|c|}{ Highly expressed in OSEC11 } \\
\hline H19,MIR675 & H19, imprinted maternally expressed transcript (non-protein coding); microRNA675 & 79.38 & 0 & NA & $8.04 \mathrm{E}-12$ \\
\hline$A R$ & Androgen receptor & 4.16 & 0 & $N A$ & $2.46 \mathrm{E}-09$ \\
\hline CALCR & Calcitonin receptor & 3.19 & 0 & $N A$ & 3.37E-06 \\
\hline DCSTAMP & Dendrocyte expressed seven transmembrane protein & 3.55 & 0 & $N A$ & $1.37 \mathrm{E}-04$ \\
\hline REN & Renin & 113.02 & 0 & $N A$ & $2.81 \mathrm{E}-04$ \\
\hline MGP & Matrix Gla protein & 56.34 & 0 & $N A$ & 3.77E-04 \\
\hline KISS1 & KiSS-1 metastasis-suppressor & 98.79 & 0 & $N A$ & $9.30 \mathrm{E}-04$ \\
\hline RP11-13 L2.4 & & 7.26 & 0 & $N A$ & $1.21 \mathrm{E}-03$ \\
\hline LEF1 & Lymphoid enhancer-binding factor 1 & 4.58 & 0 & $N A$ & $1.46 \mathrm{E}-03$ \\
\hline $\mathrm{HOXC12}$ & Homeobox C12 & 9.19 & 0 & $N A$ & $1.91 \mathrm{E}-03$ \\
\hline $\mathrm{DACH} 2$ & Dachshund homolog 2 (Drosophila) & 2.62 & 0 & $N A$ & $2.05 \mathrm{E}-03$ \\
\hline LPL & Lipoprotein lipase & 0.88 & 0 & $N A$ & $2.08 \mathrm{E}-03$ \\
\hline WNT16 & Wingless-type MMTV integration site family, member 16 & 2 & 0 & $N A$ & $2.60 \mathrm{E}-03$ \\
\hline PPP1R14A & Protein phosphatase 1 , regulatory (inhibitor) subunit $14 \mathrm{~A}$ & 10.01 & 0 & $N A$ & $6.06 \mathrm{E}-03$ \\
\hline WFDC1 & WAP four-disulfide core domain 1 & 2.49 & 0 & $N A$ & $6.57 \mathrm{E}-03$ \\
\hline SOD3 & Superoxide dismutase 3, extracellular & 11.15 & 0 & $N A$ & $6.65 \mathrm{E}-03$ \\
\hline GSTM5 & Glutathione S-transferase mu 5 & 2.37 & 0 & $N A$ & $8.57 \mathrm{E}-03$ \\
\hline MKRN3 & Makorin ring finger protein 3 & 2.24 & 0 & $N A$ & $9.50 \mathrm{E}-03$ \\
\hline LINC00460 & Long intergenic non-protein coding RNA 460 & 3.24 & 0 & $N A$ & $9.83 \mathrm{E}-03$ \\
\hline C8orf4 & Chromosome 8 open reading frame 4 & 6.8 & 0 & $N A$ & $1.20 \mathrm{E}-02$ \\
\hline PPAPDC3 & Phosphatidic acid phosphatase type 2 domain containing 3 & 3.84 & 0 & $N A$ & $1.27 \mathrm{E}-02$ \\
\hline LYPD1 & LY6/PLAUR domain containing 1 & 4.58 & 0 & $N A$ & $1.50 \mathrm{E}-02$ \\
\hline RCSD1, RP3-455 J7.4 & RCSD domain containing 1 & 1.64 & 0 & $N A$ & $1.51 \mathrm{E}-02$ \\
\hline $\mathrm{ITIH} 3$ & Inter-alpha-trypsin inhibitor heavy chain 3 & 2.11 & 0 & $N A$ & $1.59 \mathrm{E}-02$ \\
\hline MAOB & Monoamine oxidase B & 1.13 & 0 & $N A$ & $1.69 \mathrm{E}-02$ \\
\hline $\mathrm{HOXC11}$ & Homeobox C11 & 1.68 & 0 & $N A$ & $1.78 \mathrm{E}-02$ \\
\hline ITPRIPL1 & Inositol 1,4,5-trisphosphate receptor interacting protein-like 1 & 1.21 & 0 & $N A$ & $1.96 \mathrm{E}-02$ \\
\hline CD36 & CD36 molecule (thrombospondin receptor) & 1.88 & 0 & $N A$ & $2.26 \mathrm{E}-02$ \\
\hline KIAA1456 & KIAA1456 & 1.59 & 0 & $N A$ & $2.28 \mathrm{E}-02$ \\
\hline IQGAP2 & IQ motif containing GTPase activating protein 2 & 1.24 & 0 & $N A$ & $2.46 \mathrm{E}-02$ \\
\hline
\end{tabular}




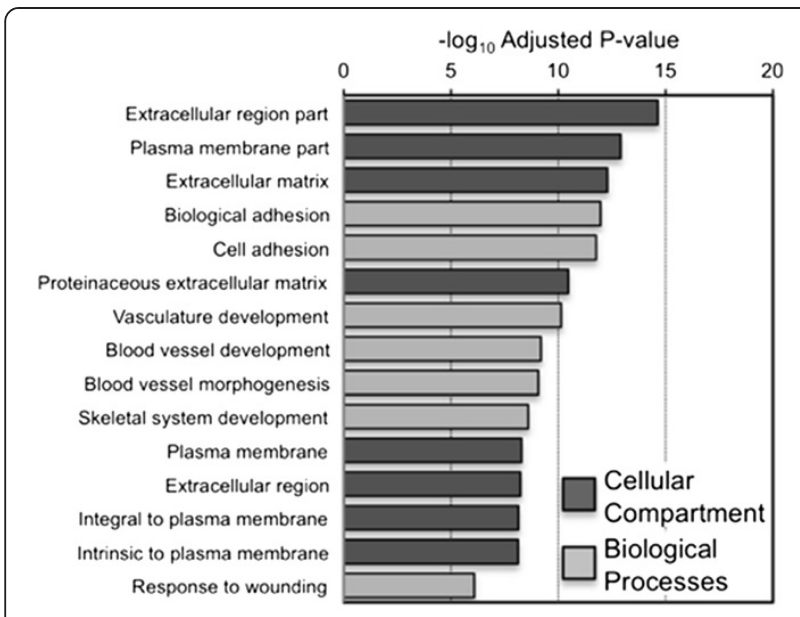

Figure 2 RNAseq analysis of the transcriptome of EEC16. Gene ontological analyses of all genes significantly differentially expressed between EEC16 and OSEC11, performed using DAVID (http://david. abcc.ncifcrf.gov) with Benjamini adjusted p-values.

indices compared to the same cells cultured in $2 \mathrm{D}$ $(17.1 \% \pm 0.7 \%$ versus $2.8 \% \pm 0.4 \%)$, whereas $\mathrm{EEC} 12 \mathrm{Z}$ in $2 \mathrm{D}$ had lower proliferative indices than 3D culture counterparts $(8.1 \% \pm 1 \%$ versus $33 \% \pm 2 \%)$ (Figure $3 \mathrm{~B}$ ).

\section{Candidate gene expression analysis of 3D cultured EEC16}

We used semi-quantitative real-time PCR (qPCR) to analyze changes in the expression of genes relevant to endometriosis biology when EEC cultures were transitioned from a $2 \mathrm{D}$ to $3 \mathrm{D}$ microenvironment (Figure $3 \mathrm{C}$ ). We focused on genes found in pathways that are involved in immune responses (such as interleukins), microenvironmental interactions (e.g. matrix metalloproteinases and growth factors) and hormonal signaling. Trends in gene expression were highly similar in the two cell line models. Several chemokines, interleukins and their receptors were significantly upregulated in 3D compared to 2D, but particularly IL6, IL8 and its receptor CXCR1, and CXCL12 and its receptor CXCR4. The microenvironmental modulators hepatocyte growth factor (HGF) and matrix metalloproteinase 2 $(M M P 2)$ were also significantly upregulated in 3D cultures. Expression of genes involved in the production of prostaglandin (cyclooxygenase 2, PTGS2) and estrogen (aromatase, CYP19A1) also tended to increase in 3D cultures. Significant downregulation of thrombospondin-1 (TSP-1), an inhibitor for neovascularization, was observed in both cell lines and vascular endothelial growth factor, a proangiogenic signaling protein, was upregulated in 3D cultures of EEC12Z, the net effect being that proangiogenic signaling is enhanced in 3D cultured EECs. Thus, 3D cultures exhibit gene expression profiles that are similar to human endometriosis, while many transcriptomic hallmarks of EMS are reduced/lost when EEC lines are cultured in 2D.

\section{Discussion}

Endometriosis is a common benign gynecological disease, with many clinical consequences for the affected patient such as infertility, chronic pain and a higher risk of ovarian cancer. There is both a basic research and clinical need for better in vitro endometriosis models to help understand the underlying biology and etiology of the disease and to identify novel therapeutic targets.

In this study, we describe establishing a novel cell culture model of ovarian endometriosis, EEC16. One challenge when culturing ovarian endometriosis tissues is avoiding contamination by stromal cells or normal adjacent ovarian epithelia. After isolation and culture, $100 \%$ of EEC16 cells expressed cytokeratins indicating the culture is epithelial in origin. Furthermore, in contrast to normal OSECs, EEC16 did not express N-Cadherin, and RNA-sequencing profiles showed a 342-fold upregulation of an endometriosis marker, keratin 19, in EEC16 compared to OSECs [19]. This suggests that EEC16 represents an uncontaminated culture of primary ovarian endometriosis epithelial cells. It is known that within endometriosis lesions heterogeneous epithelial cell populations exist. The EEC16 line appears to represent the subpopulation of cells that lack E-cadherin expression and are more invasive in vitro $[17,20]$. Consistent with this, EEC16 expressed vimentin, but not Ecadherin, was invasive and exhibited a partially transformed phenotype in in vitro assays. This is in contrast to the phenotype of other primary cells including OSECs, human mammary epithelial cells and fallopian tube epithelial cells [14]. While the novel EEC16 culture maintained expression of the majority of endometriosis markers we tested, expression of ER $\alpha$ was lost. Loss of steroid hormone receptor expression is a common in cultured endometriosis samples and this limitation can be easily circumvented by artificially overexpressing this gene [21]. The RNAseq analysis identified many genes that distinguished EEC16 and OSEC11; we propose that these genes represent novel candidate endometriosis biomarkers and/or novel drivers of endometriosis. For example expression of H19, a well known, imprinted, long-non coding RNA [22,23], was high in OSEC11 but absent in EEC16, which may suggest a role for H19 in endometriosis development. Conversely, adhesion molecules highly expressed by EEC16 (NCAM and CHL1) but showing only minimal expression in OSEC11 may perhaps be involved in the implantation of endometriosis epithelial cells onto the peritoneum and ovary. Alternatively, genes that distinguish EEC16 and OSEC11 may simply reflect normal differences between cells of ovarian and 


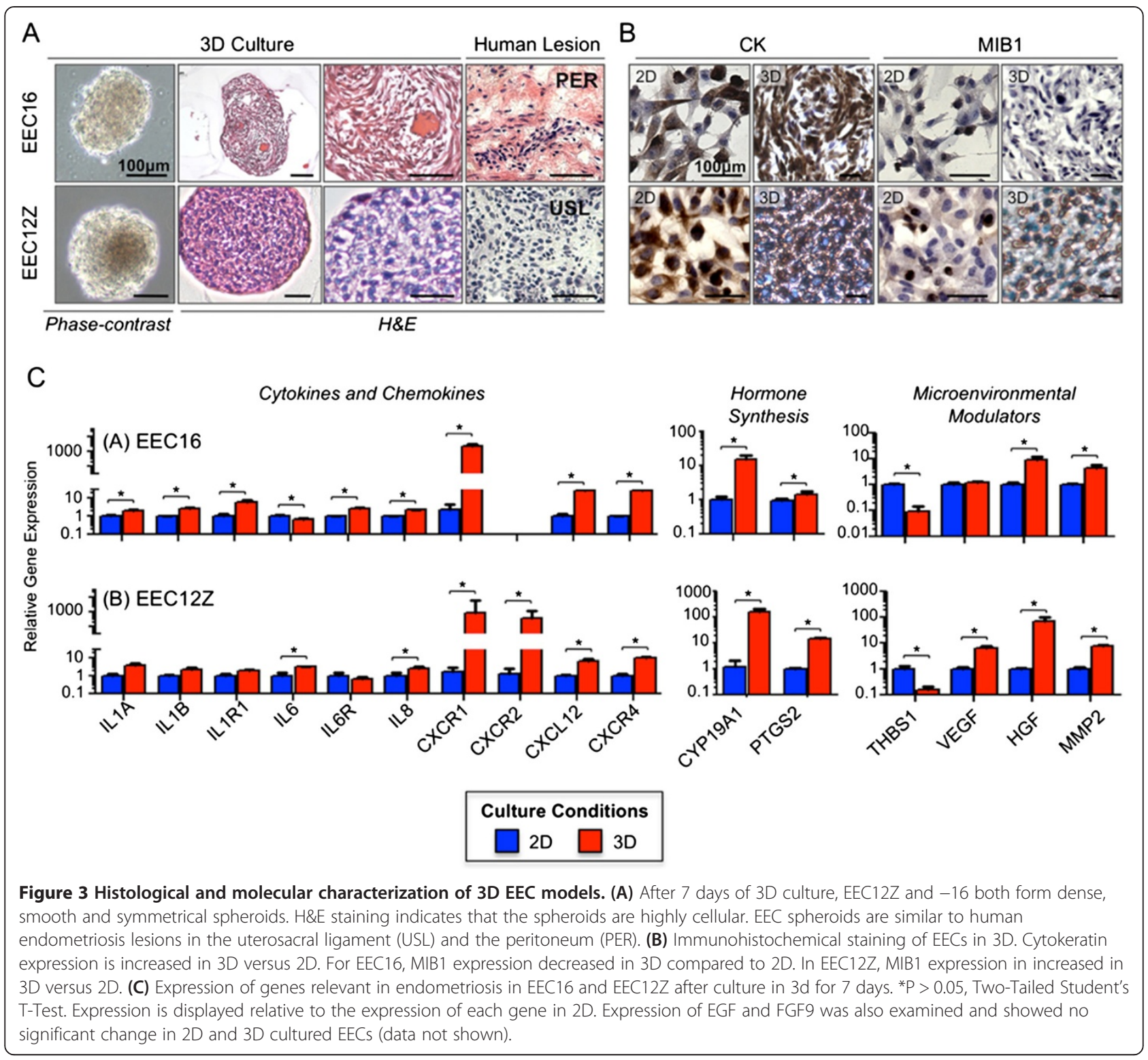

endometrial origin. Further work will be required using normal endometrial cells as a control to confirm whether the identified genes are involved in the development of endometriosis but nonetheless, a number of the candidate genes we identified warrant further study in in vitro and in vivo models of endometriosis, as well as in primary tissues.

The geometry, elasticity and tensile forces of a tissue, as well as cell-cell/cell-matrix interactions, can all influence the cellular phenotype but these factors are absent in traditional monolayer cultures. To our knowledge, this is the first report of $3 \mathrm{D}$ in vitro modeling of endometriosis as spheroids. Histologically, EEC16 spheroids were highly reminiscent of peritoneal lesions. EEC16 was from a lesion located on the ovarian surface, and we note that our observations are consistent with previous reports that find ovarian surface lesions, upon histological examination, resemble peritoneal lesions more closely than cystic endometriomas within the ovarian cortex [2]. A striking feature of the 3D endometriosis models was the close resemblance of human endometriosis lesions on a molecular level. Culturing cells in a 3D environment lead to changes in the expression of genes involved in pathophysiologic pathways responsible for the formation and growth of endometriosis lesions as well as for endometriosis related symptoms in patients. An important clinical need could be met by using these models to develop novel treatments targeting pathways such as cytokine and interleukin signaling, cellular prostaglandin and estrogen biosynthesis, growth factor and neovascularization signaling. For instance, 3D models of endometriosis could 
be used to perform high-throughput in vitro screens to identify novel small molecule inhibitor therapies for endometriosis. These highly specific drugs would potentially have the advantage of far fewer unwanted side effects than current treatment regimens.

Finally, epidemiological and histopathological studies reported that endometriosis patients have an elevated risk of developing ovarian cancers with a clear cell and endometrioid histology [3,5,6]. Numerous genes, including ARIDIA and WNT4 [24-29] have been implicated in the development of endometriosisassociated ovarian cancer. 3D models of endometriosis could now be used to study the functional role of these specific genes during tumorigenesis and to model the stepwise development from endometriosis precursor lesions to ovarian cancer.

\section{Conclusions}

Our overall conclusion is that 3D models of endometriosis are superior to existing monolayer culture techniques. It is clear that these 3D models will have diverse applications for endometriosis and ovarian cancer research. Improved understanding of the biological links between endometriosis and ovarian cancer could help to predict which endometriosis lesions are most susceptible to neoplastic transformation. In such cases women could be offered preventive surgery, intensive screening or perhaps chemoprevention. Moreover, we and others find that 2D and 3D in vitro models of malignant cells show differential responses to therapeutic agents [15,30]; since endometriosis 3D models more closely resemble the in vivo microenvironment of endometriosis, the potential for identifying and translating novel targeted therapeutic strategies will be greatly enhanced by using these models.

\section{Additional files}

Additional file 1: Table S1. Primer sequences for gene expression analysis. PCR primers were designed using Primer3 (http://primer3. sourceforge.net/) or were identified using the Harvard primer bank (http://pga.mgh.harvard.edu/primerbank/).

Additional file 2: Figure S1. E-Cadherin expression in the endometrium during the menstrual cycle. E-cadherin expression in the endometrium of women (not affected by endometriosis) is not influenced by stage of the menstrual cycle.

Additional file 3: Table S2. Gene ontology analyses of the EEC16 transcriptome. We performed a gene ontology analysis of the genes highly expressed in EEC 16 cells compared to OSEC 11. We detected a significant enrichment of genes associated with relevant biological processes in endometriosis were found such as adhesion, vasculature development migration, cell contractility, inflammatory responses, and responses to hypoxia.

\section{Abbreviations}

2D: Three-dimensional; 3D: Three-dimensional; EEC: Endometriosis epithelial cell; GO: Gene ontology; OSEC: Ovarian surface epithelial cells;
PCR: Polymerase chain reaction; RNA: Ribonucleic acid; USC: University of Southern California.

\section{Competing interests}

All authors declare that they have no financial or non-financial competing interests.

\section{Authors' contributions}

$\mathrm{DB}, \mathrm{KL}$ and $\mathrm{SAG}$ designed the study and wrote the manuscript. DB and $\mathrm{KL}$ conducted and analyzed the experiments. $C T$ collected human endometriosis tissue samples and PNR performed the karyotyping. ASP created the EEC12Z cell line used in this study. All authors contributed to and approved the final draft of the manuscript.

\section{Acknowledgements}

This research was performed at the Keck School of Medicine, University of Southern California, Los Angeles, California, USA. We thank David VanDenBerg for assistance with the RNAseq data analysis and Alex Trana and Lillian Young for pathology and immunohistochemistry services; we also thank the patients who donate the tissues that enable us to perform these studies.

\section{Grant support}

This work was supported by Departmental funds from the Departments of Preventive Medicine and Obstetrics and Gynecology at the USC Keck School of Medicine. KL is funded by National Institute of Health grant number 5 U19 CA148112-02 and an Ann Schreiber Program of Excellence award from the Ovarian Cancer Research Fund (POE/USC/01.12). The work was performed within the USC Norris Comprehensive Cancer Center, which is supported by a Cancer Center Support Grant (award number P30CA014089) from the National Cancer Institute. The content is solely the responsibility of the authors and does not necessarily represent the official views of the National Cancer Institute or the National Institutes of Health.

\section{Author details}

'Department of Obstetrics and Gynecology, University of Southern California/ Keck School of Medicine, IRD, 2020 Zonal Avenue, Los Angeles, California 90033, USA. ${ }^{2}$ Department of Cellbiology and Neuroscience, Goethe University, Max-von-Laue-Straße 13, Frankfurt am Main 60438, Germany. ${ }^{3}$ Pathology and Lab Medicine, David Geffen University of California Los Angeles, 22-26 Rehab Cntr, 1000 Veteran Ave, Los Angeles, California 90024, USA. ${ }^{4}$ Department of Preventive Medicine, University of Southern California/ Keck School of Medicine, Harlyne Norris Research Tower, NRT2517G, 1450 Biggy Street, Los Angeles, California 90033, USA.

Received: 29 August 2013 Accepted: 25 January 2014

Published: 6 February 2014

\section{References}

1. Eskenazi B, Warner ML: Epidemiology of endometriosis. Obstet Gynecol Clin North Am 1997, 24(2):235-258.

2. Bulun SE: Endometriosis. N Engl I Med 2009, 360(3):268-279.

3. Pearce CL, Templeman C, Rossing MA, Lee A, Near AM, Webb PM, Nagle CM, Doherty JA, Cushing-Haugen KL, Wicklund KG, Chang-Claude J, Hein R, Lurie G, Wilkens LR, Carney ME, Goodman MT, Moysich K, Kjaer SK, Hogdall E, Jensen A, Goode EL, Fridley BL, Larson MC, Schildkraut JM, Palmieri RT, Cramer DW, Terry $\mathrm{KL}$, Vitonis AF, Titus $\mathrm{L}$, Ziogas A, et al: Association between endometriosis and risk of histological subtypes of ovarian cancer: a pooled analysis of casecontrol studies. Lancet Oncol 2012, 13(4):385-394.

4. Nisolle M, Donnez J: Peritoneal endometriosis, ovarian endometriosis, and adenomyotic nodules of the rectovaginal septum are three different entities. Fertil Steril 1997, 68(4):585-596.

5. Sainz de la Cuesta R, Eichhorn JH, Rice LW, Fuller AF, Nikrui N, Goff BA: Histologic transformation of benign endometriosis to early epithelial ovarian cancer. Gynecol Oncol 1996, 60(2):238-244.

6. Dzatic-Smiljkovic O, Vasiljevic M, Djukic M, Vugdelic R, Vugdelic J: Frequency of ovarian endometriosis in epithelial ovarian cancer patients. Clin Exp Obstet Gynecol 2011, 38(4):394-398.

7. Banu SK, Lee J, Starzinski-Powitz A, Arosh JA: Gene expression profiles and functional characterization of human immortalized endometriotic epithelial and stromal cells. Fertil Steril 2008, 90(4):972-987. 
8. Banu SK, Starzinski-Powitz A, Speights VO, Burghardt RC, Arosh JA: Induction of peritoneal endometriosis in nude mice with use of human immortalized endometriosis epithelial and stromal cells: a potential experimental tool to study molecular pathogenesis of endometriosis in humans. Fertil Steril 2009, 91(5 Suppl):2199-2209.

9. Wu Y, Starzinski-Powitz A, Guo SW: Trichostatin A, a histone deacetylase inhibitor, attenuates invasiveness and reactivates E-cadherin expression in immortalized endometriotic cells. Reprod Sci 2007, 14(4):374-382.

10. Rai $P$, Shivaji S: The role of DJ-1 in the pathogenesis of endometriosis. PLoS One 2011, 6(3):e18074

11. Schreiner A, Ruonala M, Jakob V, Suthaus J, Boles E, Wouters F, Starzinski-Powitz A: Junction protein shrew-1 influences cell invasion and interacts with invasion-promoting protein CD147. Mol Biol Cell 2007, 18(4):1272-1281.

12. Bissell MJ, Radisky D: Putting tumours in context. Nat Rev Cancer 2001, 1(1):46-54.

13. Grun B, Benjamin E, Sinclair J, Timms JF, Jacobs IJ, Gayther SA, Dafou D: Threedimensional in vitro cell biology models of ovarian and endometrial cancer. Cell Prolif 2009, 42(2):219-228

14. Lawrenson K, Benjamin E, Turmaine M, Jacobs I, Gayther S, Dafou D: In vitro three-dimensional modelling of human ovarian surface epithelial cells. Cell Prolif 2009, 42(3):385-393.

15. Lee JM, Mhawech-Fauceglia P, Lee N, Parsanian LC, Lin YG, Gayther SA, Lawrenson K: A three-dimensional microenvironment alters protein expression and chemosensitivity of epithelial ovarian cancer cells in vitro. Lab Invest 2013, 93(5):528-542.

16. Li NF, Wilbanks G, Balkwill F, Jacobs IJ, Dafou D, Gayther SA: A modified medium that significantly improves the growth of human normal ovarian surface epithelial (OSE) cells in vitro. Lab Invest 2004, 84(7):923-931.

17. Zeitvogel A, Baumann R, Starzinski-Powitz A: Identification of an invasive, $\mathrm{N}$-cadherin-expressing epithelial cell type in endometriosis using a new cell culture model. Am J Pathol 2001, 159(5):1839-1852.

18. Neve RM, Chin K, Fridlyand J, Yeh J, Baehner FL, Fevr T, Clark L, Bayani N, Coppe JP, Tong F, Speed T, Spellman PT, DeVries S, Lapuk A, Wang NJ, Kuo WL, Stilwell JL, Pinkel D, Albertson DG, Waldman FM, McCormick F, Dickson RB, Johnson MD, Lippman M, Ethier S, Gazdar A, Gray JW: A collection of breast cancer cell lines for the study of functionally distinct cancer subtypes. Cancer Cell 2006, 10 (6):515-527.

19. van der Linden PJ, Dunselman GA, de Goeij AF, van der Linden EP, Evers JL, Ramaekers FC: Epithelial cells in peritoneal fluid-of endometrial origin? Am J Obstet Gynecol 1995, 173(2):566-570

20. Gaetje R, Kotzian S, Herrmann G, Baumann R, Starzinski-Powitz A: Nonmalignant epithelial cells, potentially invasive in human endometriosis, lack the tumor suppressor molecule E-cadherin. Am J Pathol 1997, 150(2):461-467.

21. Bono Y, Kyo S, Takakura M, Maida Y, Mizumoto Y, Nakamura M, Nomura K, Kiyono $\mathrm{T}$, Inoue $\mathrm{M}$ : Creation of immortalised epithelial cells from ovarian endometrioma. Br J Cancer 2012, 106(6):1205-1213.

22. Ferguson-Smith AC, Sasaki H, Cattanach BM, Surani MA: Parental-originspecific epigenetic modification of the mouse H19 gene. Nature 1993, 362(6422):751-755.

23. Hao Y, Crenshaw T, Moulton T, Newcomb E, Tycko B: Tumour-suppressor activity of H19 RNA. Nature 1993, 365(6448):764-767.

24. Pagliardini L, Gentilini D, Vigano' P, Panina-Bordignon P, Busacca M, Candiani M, Di Blasio AM: An Italian association study and meta-analysis with previous GWAS confirm WNT4, CDKN2BAS and FN1 as the first identified susceptibility loci for endometriosis. J Med Genet 2013, 50(1):43-46

25. Nyholt DR, Low SK, Anderson CA, Painter JN, Uno S, Morris AP, MacGregor S, Gordon SD, Henders AK, Martin NG, Attia J, Holliday EG, McEvoy M, Scott RJ, Kennedy SM, Treloar SA, Missmer SA, Adachi S, Tanaka K, Nakamura Y, Zondervan KT, Zembutsu H, Montgomery GW: Genome-wide association meta-analysis identifies new endometriosis risk loci. Nat Genet 2012, 44(12):1355-1359.

26. Wiegand KC, Lee AF, Al-Agha OM, Chow C, Kalloger SE, Scott DW, Steidl C, Wiseman SM, Gascoyne RD, Gilks B, Huntsman DG: Loss of BAF250a (ARID1A) is frequent in high-grade endometrial carcinomas. $J$ Pathol 2011, 224(3):328-333.

27. Lowery WJ, Schildkraut JM, Akushevich L, Bentley R, Marks JR, Huntsman D, Berchuck A: Loss of ARID1A-associated protein expression is a frequent event in clear cell and endometrioid ovarian cancers. Int J Gynecol Cancer 2012, 22(1):9-14.
28. Tsuchiya A, Sakamoto M, Yasuda J, Chuma M, Ohta T, Ohki M, Yasugi T, Taketani Y, Hirohashi S: Expression profiling in ovarian clear cell carcinoma: identification of hepatocyte nuclear factor- 1 beta as a molecular marker and a possible molecular target for therapy of ovarian clear cell carcinoma. Am J Pathol 2003, 163(6):2503-2512.

29. Obata K, Morland SJ, Watson RH, Hitchcock A, Chenevix-Trench G, Thomas EJ, Campbell IG: Frequent PTEN/MMAC mutations in endometrioid but not serous or mucinous epithelial ovarian tumors. Cancer Res 1998, 58(10):2095-2097.

30. Dit Faute MA, Laurent L, Ploton D, Poupon MF, Jardillier JC, Bobichon H: Distinctive alterations of invasiveness, drug resistance and cell-cell organization in 3D-cultures of MCF-7, a human breast cancer cell line, and its multidrug resistant variant. Clin Exp Metastasis 2002, 19(2):161-168.

doi:10.1186/1757-2215-7-17

Cite this article as: Brueggmann et al: Novel three-dimensional in vitro models of ovarian endometriosis. Journal of Ovarian Research 2014 7:17.

\section{Submit your next manuscript to BioMed Central and take full advantage of:}

- Convenient online submission

- Thorough peer review

- No space constraints or color figure charges

- Immediate publication on acceptance

- Inclusion in PubMed, CAS, Scopus and Google Scholar

- Research which is freely available for redistribution

Submit your manuscript at www.biomedcentral.com/submit
C Biomed Central 